\title{
Real time implementation of fuzzy gain-scheduled PID controller for twin rotor MIMO system (TRMS)
}

\author{
Mohammed Zinelaabidine Ghellab ${ }^{1 *}$, Samir Zeghlache ${ }^{1}$, Abderrahmen Bouguerra ${ }^{2}$ \\ ${ }^{1}$ Laboratoire d'Analyse des Signaux et Systèmes, Department of Electronics, Faculty of Technology, University Mohamed \\ Boudiaf of M'sila, BP 166, Ichbilia 28000, Algeria \\ ${ }^{2}$ Laboratoire de Génie Electrique, Department of Electrical Engineering, Faculty of Technology, University Mohamed Boudiaf \\ of M'sila, BP 166, Ichbilia 28000, Algeria \\ Corresponding Author Email: ghe.mohamed@yahoo.fr
}

https://doi.org/10.18280/ama_c.730403

Received: 12 June 2018

Accepted: 15 October 2018

\section{Keywords:}

gain-adaptive PID, FGSPID, TRMS model, fuzzy system, PID control

\begin{abstract}
The work has done in this paper concern a strategy of control based on gain adaptive proportional integral derivative (PID) using the fuzzy inference system and their application to the Twin Rotor MIMO System (TRMS), the PID controller with fixed parameters may fail to provide acceptable control performance. To improve the PID control effect, new designs of the fuzzy gain Scheduled PID controller (FGSPID) were presented in this paper. The proposed techniques were applied to the TRMS, where adaptive PID controllers were proposed for control system in the presence of external disturbances. The parameters of PID controller were adjusted by a fuzzy system, used to tune in real-time the controller gain. The obtained simulation and experiment results show that the robustness of TRMS angles (pitch and yaw) driven by proposed controller are guaranteed.
\end{abstract}

\section{INTRODUCTION}

In recent years, interest in aeronautical systems has steadily increased. These systems of vertical flight, called drones, were used, initially, in the military field, in missions of recognition, of surveillance and also in an offensive role. As computer technologies, sensor design and actuators progress, drones have also improved. Nowadays, we can find civil applications such as road traffic surveillance, surveillance and environmental protection, search and rescue of wounded, and surveillance of major infrastructures (power lines, dams and bridges) $[1,2]$. For decades, several researchers have been interested in aeronautical systems, have looked at the problem of aircraft and helicopters control, this attraction to the aeronautics can be explained by several reasons, one of these reasons is that the aeronautical systems became very complex and therefore difficult to control and that the requirements in precision, speed and efficiency are mutated very much increased.

\subsection{Background}

The twin rotor multi-input multi-output system (TRMS) is an aerodynamical system similar to a helicopter, it is a highly coupled nonlinear system designed for the development and implementation of new control laws [3, 4]. Many efforts have been made to control the TRMS and some strategies have been developed to solve the path following problems for this type of system. In [5] authors presented the Model reference adaptive control for TRMS system, where a minimal controller synthesis (MCS) was utilized to TRMS system in decoupled control design. Parallel distributed fuzzy LQR controllers are designed to control the position of the pitch and yaw angles to cover various operating has been used in [6]. The sliding mode control, characterized by its robustness against non linearity and parametric variations and its effectiveness in disturbance rejection [7, 8], in [9] a terminal sliding mode control is designed to a linearized model of the TRMS system. In [10], the authors have used an adaptive second-order sliding mode controller to control the TRMS system. Design and real-time implementation of a decentralized sliding mode controller for TRMS system is presented in [11]. The major drawback is the chattering phenomenon that existing in the control signals caused by the discontinuous controls which can damage the actuators.

Due to its simple structure, simplicity of implementation and satisfactory control performance, the PID (Proportional Integral - Derivative) controller remains, until today, the most used regulator in industry. There are two main categories of this type of controller: fixed parameter and adaptive gains PID controllers. One of the most commonly used methods for determining the gains of a fixed parameter regulator is the Ziegler-Nichols method. This method has been addressed in many researches [12].

In most control applications, due to structural changes the controlled system may lose its effectiveness, therefore the PID gains need to be continuously retuned during the system life span. To reduce the effort of retuning the gains and also in order to increase system's performance, in the second group of controllers, the gains are adapted online. In [13] genetic algorithm based PID control has been utilized for the control of the TRMS, in [14] authors presented the evolutionary computation based on the genetic algorithm for the parameters optimization of the integral-proportional differential (I-PD) control to the TRMS system.

In some studies, the PID controller technique and fuzzy logic have been combined to develop effective control systems for uncertain nonlinear systems. The authors in [15-19] are 
proposed a new PID scheme in which the controller gains are scheduled by a fuzzy inference scheme, a comparison between classical control techniques and intelligent control based on fuzzy logic and genetic algorithm is presented in [20]. Authors in [21] have utilized genetic algorithm (GA) and an intelligent control scheme uses a fuzzy switching method, many gain scheduling methods have been studied and compared in [2224].

In this work, adaptive fuzzy gain scheduled PID control approaches for a TRMS system was proposed. A fuzzy inference scheme is used to tune in real-time the controller gains, where the tracking error and the change in tracking error are used in this fuzzy scheduler to make the system act faster and more effectively robust to the external disturbances. The proposed control laws are highlighted by simulations and real time implementation providing satisfactory results. Finally the proposed PID controller is compared with the conventional one through an experimental application to the TRMS system.

Compared to previous studies on PID control [13, 14, 25, 26], the proposed control approach increases the robustness of the controller with respect to external disturbances. Compared to sliding mode control $[9,11]$, the proposed control approach does not contain chattering phenomenon and obtained a good dynamic response. Compared to boundary layer sliding mode control [2,10] and higher order sliding mode control, the control approach can schedule the control gains adaptively based on the tracking error and the change of the tracking error. The contributions of this paper could be briefly summarized as follows.

1) An effective and robust controller is developed for TRMS system with the yaw and pitch external disturbances.

2) A fuzzy logic system is designed to schedule the switching gains adaptively according to the fuzzy rules based on tracking error and the change of the tracking error, which obtained a good dynamic response.

The rest of the paper is organized as follows. Section 2 focuses on the nonlinear dynamic model of the 2-DOF helicopter (TRMS). Design of the fuzzy adaptive PID controller is highlighted in section 3. Simulation results and related discussions are given in section 4 . The experimental results to validate the effectiveness of the proposed approach are presented in Section 5. Finally some conclusions are drawn in section 6 .

\section{MODEL DESCRIPTION OF THE 2-DOF HELICOPTER (TRMS)}

The behaviour of a nonlinear TRMS [27], Fig.1, in certain aspects resembles that of a helicopter. It can be well seen as a static test rig for an air vehicle with formidable control challenges. This TRMS consists of a beam pivoted on its base in such a way that it can rotate freely in both its horizontal and vertical planes. There are main and tail rotors driven by DC motors, at each end of the beam. The two rotors are controlled by variable speed electric motors enabling the helicopter to rotate in a vertical plan (pitch noted $\psi$ ) and horizontal plane (yaw noted $\varphi$ ). The tail rotor could be rotated in either direction, allowing the helicopter to yaw right or left. The motion of the helicopter was damped by a pendulum, which hung from a central pivot point. The mathematical model of the TRMS is developed under following assumptions.
- The dynamics of the propeller subsystem can be described by first-order differential equations.

- The friction in the system is of the viscous type.

Based on Lagrange's equations, we can classify the mechanical system into two parts, the forces around the horizontal axis and the forces around the vertical axis.

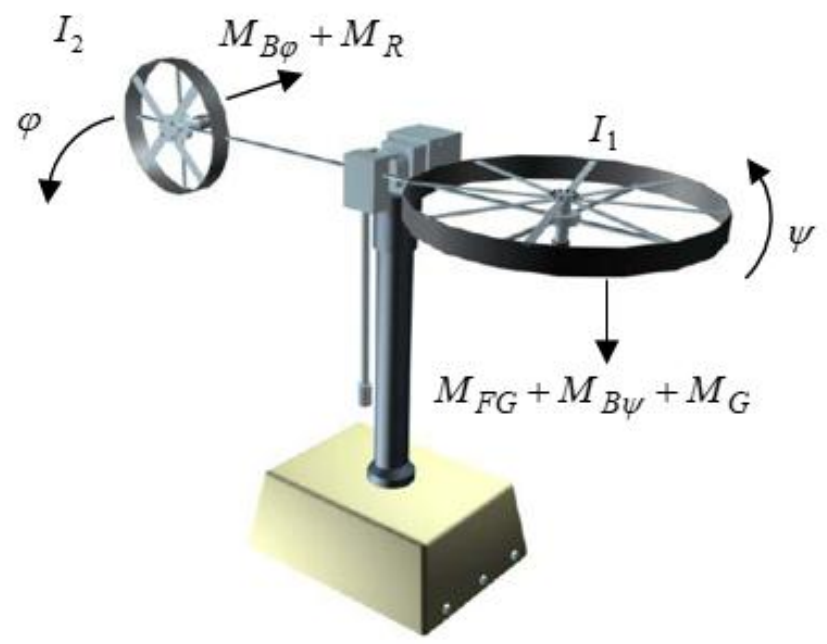

Figure 1. TRMS system configuration

The parameters of the TRMS system are $M_{F G}$ is the gravity momentum, $M_{B \psi}$ and $M_{B \varphi}$ are the frictions forces momentum, $M_{G}$ is the gyroscopic momentum, $M_{R}$ is the cross reaction momentum approximation, $I_{1}$ is the moment of inertia of vertical rotor and $I_{2}$ is the moment of inertia of horizontal rotor.

Consider the rotation of the beam in the vertical plane (around the horizontal axis). The driving torques is produced by the propellers, and the rotation can be described in principle as the motion of a pendulum. We can write the equations describing this motion as follows.

\subsection{The main rotor model}

The following momentum equation can be derived for the vertical movement:

$I_{1} \ddot{\psi}=M_{1}-M_{F G}-M_{B \psi}-M_{G}$

where the main propeller thrust $M_{1}$ is a nonlinear function of the DC motor momentum described by:

$M_{1}=a_{1} \tau_{1}^{2}+b_{1} \tau_{1}$

$a_{1}$ and $b_{1}$ are the statics characteristics parameters

The mathematical model of main rotor is given by:

$\frac{d \tau_{1}}{d t}=\frac{k_{11}}{T_{11}} u_{\psi}-\frac{T_{10}}{T_{11}} \tau_{1}$

where $u_{\psi}$ is the input voltage of the DC motor, $T_{10}, T_{11}$ is the pulsation and the time constant of the main rotor respectively and $k_{11}$ is the static gain of the DC motor.

Applying the Laplace transform to equation (2) yields: 
$\tau_{1}=\frac{k_{11}}{T_{11} s+T_{10}} u_{\psi}$

$M_{F G}=M_{g} \sin (\psi)$

$M_{B \psi}=B_{1 \psi} \dot{\psi}$

$M_{G}=K_{g y} M_{1} \dot{\varphi} \cos (\psi)-K_{g x} \dot{\varphi}^{2} \sin (2 \psi)$

\subsection{The tail rotor model}

Similarly, we can describe the motion of the beam in the horizontal plane motion:

$I_{2} \ddot{\varphi}=M_{2}-M_{B \phi}-M_{R}$

where the tail propeller thrust $M_{2}$ is a nonlinear function of the DC motor momentum described by:

$M_{2}=a_{2} \tau_{2}^{2}+b_{2} \tau_{2}$

$a_{2}$ and $b_{2}$ are the statics characteristics parameters

The mathematical model of tail rotor is given by:

$\frac{d \tau_{2}}{d t}=\frac{k_{22}}{T_{21}} u_{\varphi}-\frac{T_{20}}{T_{21}} \tau_{2}$

where $u_{\varphi}$ is the input voltage of the DC motor, $T_{20}, T_{21}$ is the pulsation and the time constant of the main rotor respectively and $k_{11}$ is the static gain of the DC motor.

Applying the Laplace transform to equation (2) yields:

$\tau_{2}=\frac{k_{22}}{T_{21} s+T_{20}} u_{\varphi}$

$u_{\varphi}$ is the input voltage of the DC motor, $T_{21}$ is the time constant of the main rotor and $k_{22}$ is the static gain DC motor.

$M_{B \varphi}=B_{1 \varphi} \dot{\varphi}$

$M_{R}=\frac{k_{c}\left(T_{0} s+1\right)}{T_{p} s+1} M_{1}$

The dynamics of the TRMS system are described as follows

$$
\left\{\begin{array}{l}
\ddot{\psi}=\frac{1}{I_{1}}\left\{-M_{g} \sin (\psi)-B_{1 \psi} \dot{\psi}+k_{g x} \dot{\varphi}^{2} \sin (2 \psi)-\left(a_{1} \tau_{1}^{2}+b_{1} \tau\right.\right. \\
\ddot{\varphi}=\frac{1}{I_{2}}\left\{-B_{1 \varphi} \dot{\varphi}-\frac{k_{c}\left(T_{0} s+1\right)}{T_{p} s+1}\left(a_{1} \tau_{1}^{2}+b_{1} \tau_{1}\right)+a_{2} \tau_{2}^{2}+b_{2} \tau_{2}\right.
\end{array}\right.
$$

Fig. 2 shows the block diagram of the TRMS helicopter, where is characterized by cross-coupling, complex dynamics and it is noted that some of its states are not accessible for measurement.

The definitions of all constants and parameters of the TRMS helicopter model are given in Table 1 .

Table 1. The parameters of the TRMS [27]

\begin{tabular}{|c|c|c|}
\hline Symbol & Definition & Value \\
\hline$I_{1}$ & $\begin{array}{l}\text { Moment of inertia of } \\
\text { vertical rotor }\end{array}$ & $6.8 \times 10^{-2} \mathrm{~kg} . \mathrm{m}^{2}$ \\
\hline$I_{2}$ & $\begin{array}{l}\text { Moment of inertia of } \\
\text { horizontal rotor }\end{array}$ & $2 \times 10^{-2} \mathrm{~kg} \cdot \mathrm{m}^{2}$ \\
\hline$a_{1}$ & $\begin{array}{c}\text { Static characteristic } \\
\text { parameter }\end{array}$ & 0.0135 \\
\hline$b_{1}$ & $\begin{array}{l}\text { Static characteristic } \\
\text { parameter }\end{array}$ & 0.0924 \\
\hline$a_{2}$ & $\begin{array}{l}\text { Static characteristic } \\
\text { parameter }\end{array}$ & 0.02 \\
\hline$b_{2}$ & $\begin{array}{l}\text { Static characteristic } \\
\text { parameter }\end{array}$ & 0.09 \\
\hline$M_{g}$ & Gravity momentum & 0.32 \\
\hline$B_{1 \psi}$ & $\begin{array}{l}\text { Friction momentum } \\
\text { parameter }\end{array}$ & $6 \times 10^{-3}$ N.m.s / rad \\
\hline$B_{1 \varphi}$ & $\begin{array}{l}\text { Friction momentum } \\
\text { parameter }\end{array}$ & $1 \times 10^{-1}$ N.m.s / rad \\
\hline$K_{g y}$ & $\begin{array}{c}\text { Gyroscopic momentum } \\
\text { parameter }\end{array}$ & $0.05 \mathrm{~s} / \mathrm{rad}$ \\
\hline$K_{g x}$ & $\begin{array}{l}\text { Gyroscopic momentum } \\
\text { parameter }\end{array}$ & $0.0163 \mathrm{~s} / \mathrm{rad}$ \\
\hline$k_{11}$ & Motor 1 gain & 1.1 \\
\hline$k_{22}$ & Motor 2 gain & 0.8 \\
\hline$T_{11}$ & $\begin{array}{l}\text { Motor } 1 \text { denominator } \\
\text { parameter }\end{array}$ & 1.2 \\
\hline$T_{10}$ & $\begin{array}{l}\text { Motor } 1 \text { denominator } \\
\text { parameter }\end{array}$ & 1 \\
\hline$T_{22}$ & $\begin{array}{l}\text { Motor } 2 \text { denominator } \\
\text { parameter }\end{array}$ & 1 \\
\hline$T_{20}$ & $\begin{array}{l}\text { Motor } 2 \text { denominator } \\
\text { parameter }\end{array}$ & 1 \\
\hline$T_{\mathrm{p}}$ & $\begin{array}{c}\text { Cross reaction momentum } \\
\text { parameter }\end{array}$ & 2 \\
\hline$T_{0}$ & $\begin{array}{c}\text { Cross reaction momentum } \\
\text { parameter }\end{array}$ & 3.5 \\
\hline$k_{c}$ & $\begin{array}{c}\text { Cross reaction momentum } \\
\text { gain }\end{array}$ & -0.2 \\
\hline $\begin{array}{c}u_{1} \text { and } \\
u_{2}\end{array}$ & $\begin{array}{l}\text { The bound for control } \\
\text { signal }\end{array}$ & {$[-2.5,+2.5] V$} \\
\hline
\end{tabular}




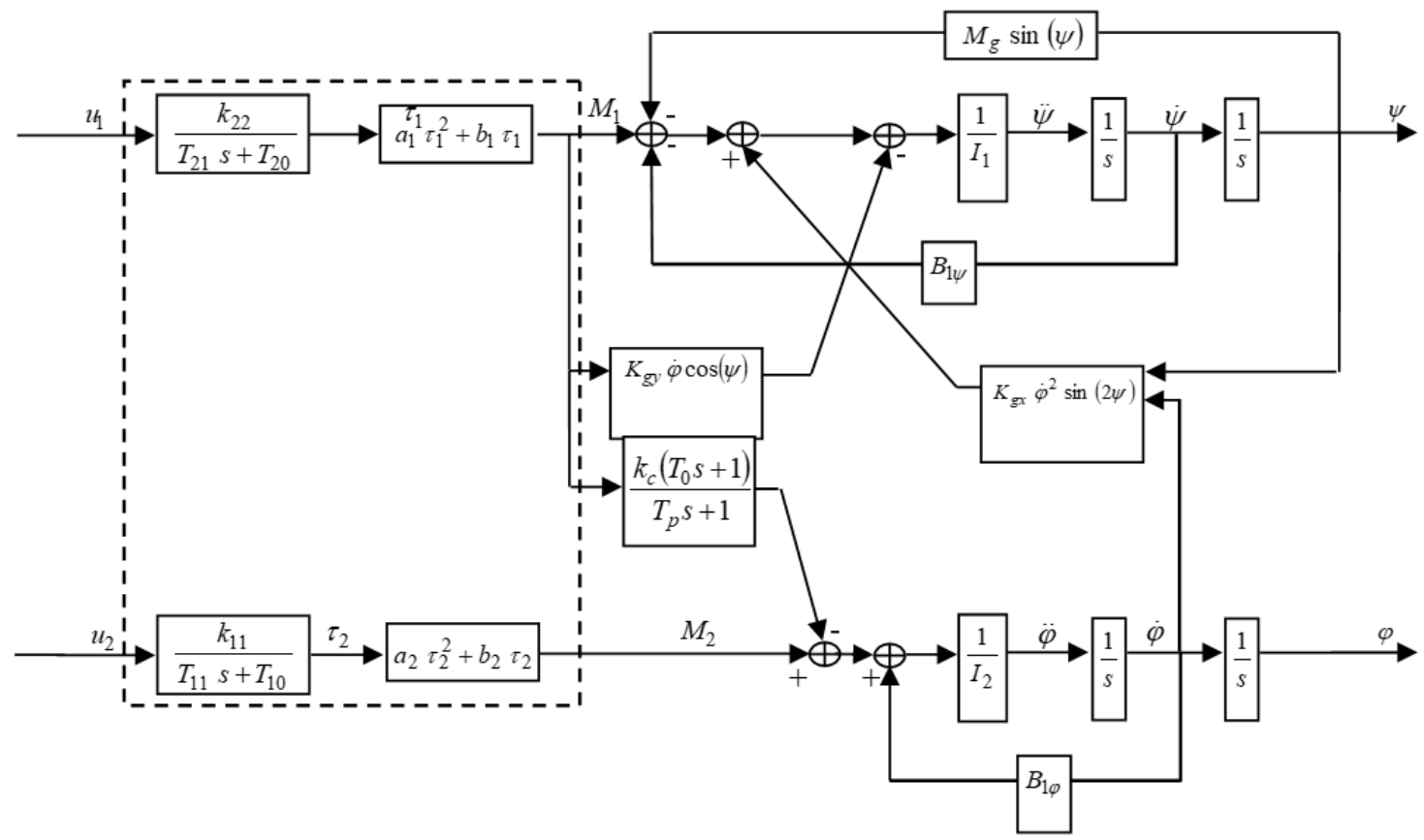

Figure 2. Block diagram of the TRMS system

\section{FUZZY ADAPTIVE PID CONTROLLER DESIGN FOR TRMS SYSTEM}

Conventional PID controllers are is a generic control loop feedback mechanism (controller) widely used in industrial control systems. They are simple and easy to use. But one of the main drawbacks of these controllers is that there is no certain way for choosing the control parameters which guarantees the good performance. Therefore in real world applications these gains need to be fine-tuned to keep the required performance. To overcome this shortcoming, Fuzzy Logic Controller is used to tune PID gains online where the tracking error and the change of the tracking error are used to determine control parameters $k_{p}, k_{i}$ and $k_{d}$.

$u_{P I D}=k_{p} e(t)+k_{i} \int_{0}^{t} e(\tau) d \tau+k_{d} \frac{d e(t)}{d t}$

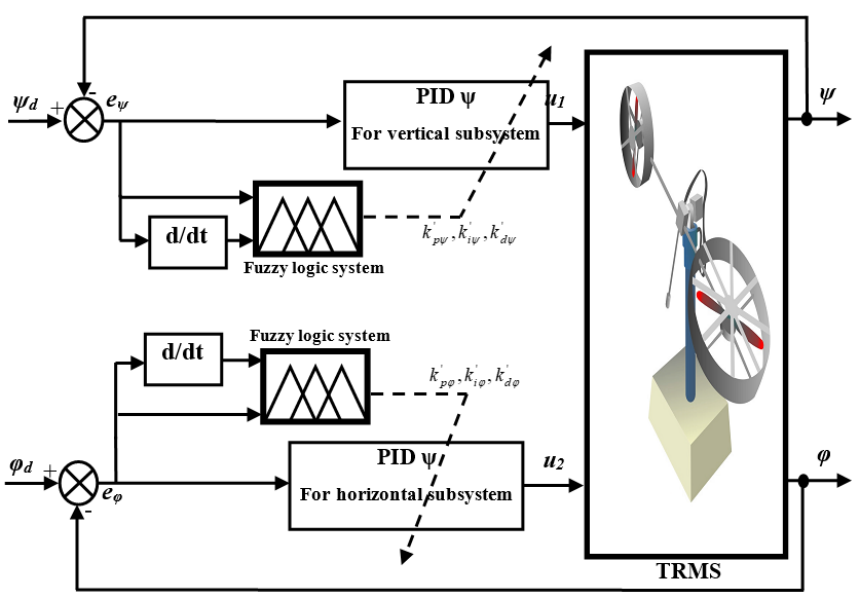

Figure 3. Block diagram of TRMS with FGSPID controller
In this section, designing the adaptive PID controller using the fuzzy logic will be studied. In order to control the TRMS with two degrees of freedom, two fuzzy adaptive PID controllers need to be developed: one for the horizontal axis and the other one for the vertical axis. Then, the fuzzy logic is used for updating parameters of these PID controllers. The structure of fuzzy adaptive PID controller system is shown in Fig.3.

The proposed control (FGSPID) is an approach to systematically determine the gains $k_{p}, k_{i}$ and $k_{d}$, so that the FGSPID Controller is used to tune PID gains online where the tracking error and its first time difference are used to determine control parameters. The fuzzy tuner has two inputs, error $(e)$ and error derivative $(\Delta e)$, and two outputs are $k_{p}, k_{i}$ and $k_{d}$.

The parameters of the PID controller used in the direct chain, $k_{p}, k_{i}$ and $k_{d}$, are normalized into the range between zero and one by using the following linear transformations [28-30]:

$\left\{\begin{array}{l}k_{p}^{\prime}=\left(k_{p}-k_{P \min }\right) /\left(k_{P \max }-k_{P \min }\right) \\ k_{i}^{\prime}=\left(k_{i}-k_{i \min }\right) /\left(k_{i \max }-k_{i \min }\right) \\ k_{d}^{\prime}=\left(k_{d}-k_{d \text { min }}\right) /\left(k_{d \max }-k_{d \text { min }}\right)\end{array}\right.$

The parameters $k_{p}, k_{i}$ and $k_{d}$ are determined by a set of linguistic rules of the FGSPID controller structure, as following:

If $\boldsymbol{e}(\boldsymbol{k})$ is $\boldsymbol{A}_{\boldsymbol{i}}$, and $\Delta \boldsymbol{e}(\boldsymbol{k})$ is $\boldsymbol{B}_{\boldsymbol{i}}$, then $\boldsymbol{k}_{\boldsymbol{p}}^{\prime}$ is $\boldsymbol{C}_{\boldsymbol{i}}, \boldsymbol{k}_{\boldsymbol{i}}^{\prime}$ is $\boldsymbol{D}_{\boldsymbol{i}}$ and $\boldsymbol{k}_{\boldsymbol{d}}$ is $\boldsymbol{E}_{\boldsymbol{i}}$.

where: $A_{i}, B_{i}, C_{i}, D_{i}$ and $E_{i}$ are fuzzy sets corresponding to $e$ $(k), \Delta e(k), k_{p}, k_{i}$ and $k_{d}$ respectively.

The application of FGSPID control to the TRMS corresponds to adapt the different gains $k_{p}, k_{i}$ and $k_{d}$ for the horizontal and vertical subsystems. The main advantage of this adaptation is to synthesize the six gains in the same time and in the same way, in order to stabilize both pitch and yaw angles while tracking the desired trajectories, to compensate the 
internal and external disturbances and to guarantee the robustness.

The block diagram of the FGSPID applied to the TRMS is shown in Fig.3. When $k_{p j}^{\prime}, k_{i j}^{\prime}$ and $k_{d j}^{\prime}$ with $(j=\psi, \varphi)$ for each horizontal and vertical subsystem are obtained by a fuzzy inference system, the gains $k_{p j}$, $k_{i j}$ and $k_{d j}$ with $(j=\psi, \varphi)$ of the PID regulator for each subsystem are calculated by the equation:

$$
\left\{\begin{array}{l}
k_{p j}=\left(k_{p j \max }-k_{P j \min }\right) k_{p j}^{\prime}+k_{P j \min } \\
k_{i j}=\left(k_{i j \max }-k_{i j \min }\right) k_{i j}^{\prime}+k_{i j \min } \\
k_{d j}=\left(k_{d j \max }-k_{d j \min }\right) k_{d j}^{\prime}+k_{d j \min } \quad \text { with }(j=\psi, \varphi)
\end{array}\right.
$$
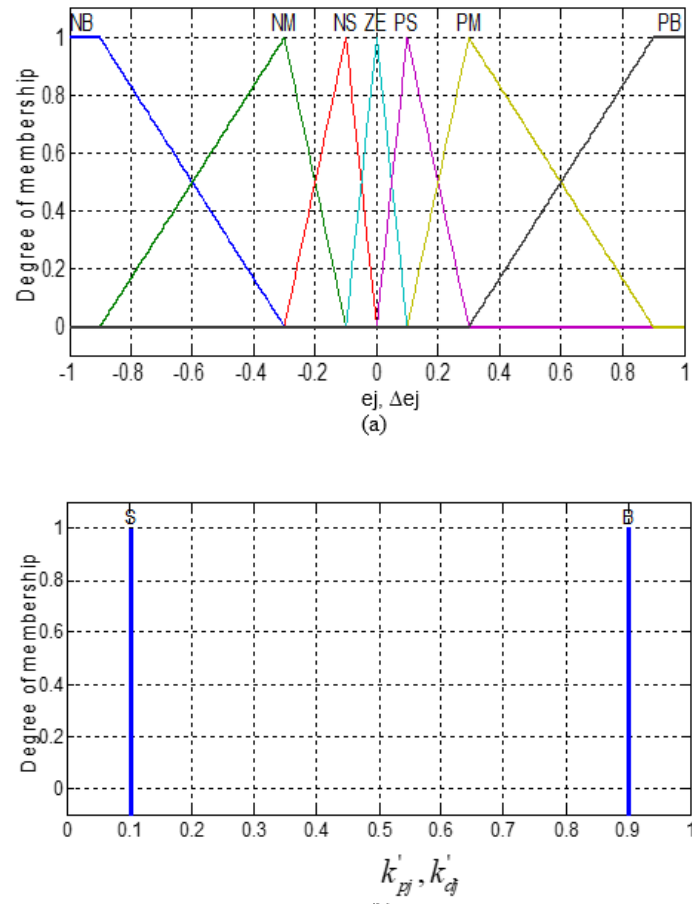

(b)

Figure 4. Fuzzy Membership functions of the inputs $e_{j}$ and $\Delta e_{j}$ and the outputs $k_{p j}^{\prime}, k_{d j}^{\prime}$ with $(j=\psi, \varphi)$ [31]
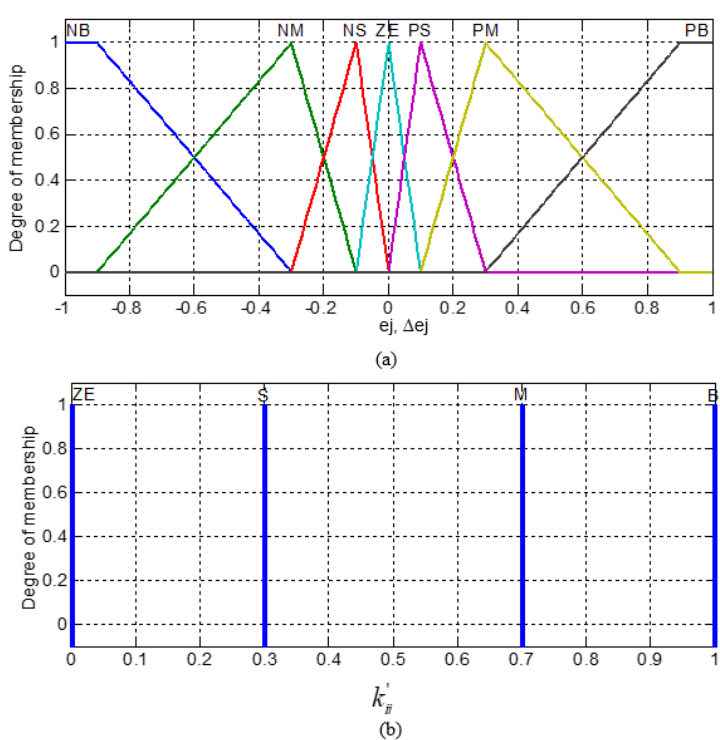

Figure 5. Fuzzy Membership functions of the inputs $e_{j}$ and $\Delta e_{j}$ and the output $k_{i j}^{\prime}$ with $(j=\psi, \varphi)[31]$
The membership functions for the inputs $e_{j}$ and $\Delta e_{j}$ with $(j=\psi, \varphi)$ are defined in the range $[-1,1]$ and chosen to be triangular identical shapes as indicated in Fig.4 and Fig.5.

They are quantized into seven levels represented by a set of linguistic variables defined as follows:

(NB): negative big.

(NM): negative medium.

(PM): Positive medium.

(NS): Negative small.

(PB): Positive big.

Table.1, Table. 2 and Table. 3 shows the linguist rules of the $k_{p j}, k_{i j}$ and $k_{d j}$ used in the FGSPID Controller [31].

Table 2. Fuzzy tuning rules for $k_{p j}^{\prime}[31]$

\begin{tabular}{|c|c|c|c|c|c|c|c|}
\hline$e_{j} \Delta e_{j}$ & $\mathrm{NB}$ & $\mathrm{NM}$ & $\mathrm{NS}$ & $\mathrm{ZE}$ & $\mathrm{PS}$ & $\mathrm{PM}$ & $\mathrm{PB}$ \\
\hline $\mathrm{NB}$ & $\mathrm{B}$ & $\mathrm{B}$ & $\mathrm{B}$ & $\mathrm{B}$ & $\mathrm{B}$ & $\mathrm{B}$ & $\mathrm{B}$ \\
\hline $\mathrm{NM}$ & $\mathrm{S}$ & $\mathrm{B}$ & $\mathrm{B}$ & $\mathrm{B}$ & $\mathrm{B}$ & $\mathrm{B}$ & $\mathrm{S}$ \\
\hline $\mathrm{NS}$ & $\mathrm{S}$ & $\mathrm{S}$ & $\mathrm{B}$ & $\mathrm{B}$ & $\mathrm{B}$ & $\mathrm{S}$ & $\mathrm{S}$ \\
\hline $\mathrm{ZE}$ & $\mathrm{S}$ & $\mathrm{S}$ & $\mathrm{S}$ & $\mathrm{B}$ & $\mathrm{S}$ & $\mathrm{S}$ & $\mathrm{S}$ \\
\hline $\mathrm{PS}$ & $\mathrm{S}$ & $\mathrm{S}$ & $\mathrm{B}$ & $\mathrm{B}$ & $\mathrm{B}$ & $\mathrm{S}$ & $\mathrm{S}$ \\
\hline $\mathrm{PM}$ & $\mathrm{S}$ & $\mathrm{B}$ & $\mathrm{B}$ & $\mathrm{B}$ & $\mathrm{B}$ & $\mathrm{B}$ & $\mathrm{S}$ \\
\hline $\mathrm{PB}$ & $\mathrm{B}$ & $\mathrm{B}$ & $\mathrm{B}$ & $\mathrm{B}$ & $\mathrm{B}$ & $\mathrm{B}$ & $\mathrm{B}$ \\
\hline
\end{tabular}

Table 3. Fuzzy tuning rules for $k_{i j}^{\prime}[31]$

\begin{tabular}{|c|c|c|c|c|c|c|c|}
\hline$e_{j} \Delta e_{j}$ & $\mathrm{NB}$ & $\mathrm{NM}$ & $\mathrm{NS}$ & $\mathrm{ZE}$ & $\mathrm{PS}$ & $\mathrm{PM}$ & $\mathrm{PB}$ \\
\hline $\mathrm{NB}$ & $\mathrm{B}$ & $\mathrm{B}$ & $\mathrm{B}$ & $\mathrm{B}$ & $\mathrm{B}$ & $\mathrm{B}$ & $\mathrm{B}$ \\
\hline $\mathrm{NM}$ & $\mathrm{M}$ & $\mathrm{M}$ & $\mathrm{B}$ & $\mathrm{B}$ & $\mathrm{B}$ & $\mathrm{M}$ & $\mathrm{M}$ \\
\hline $\mathrm{NS}$ & $\mathrm{S}$ & $\mathrm{M}$ & $\mathrm{M}$ & $\mathrm{B}$ & $\mathrm{M}$ & $\mathrm{M}$ & $\mathrm{S}$ \\
\hline $\mathrm{ZE}$ & $\mathrm{ZE}$ & $\mathrm{S}$ & $\mathrm{M}$ & $\mathrm{B}$ & $\mathrm{M}$ & $\mathrm{S}$ & $\mathrm{ZE}$ \\
\hline $\mathrm{PS}$ & $\mathrm{S}$ & $\mathrm{M}$ & $\mathrm{M}$ & $\mathrm{B}$ & $\mathrm{M}$ & $\mathrm{M}$ & $\mathrm{S}$ \\
\hline $\mathrm{PM}$ & $\mathrm{M}$ & $\mathrm{M}$ & $\mathrm{B}$ & $\mathrm{B}$ & $\mathrm{B}$ & $\mathrm{M}$ & $\mathrm{M}$ \\
\hline $\mathrm{PB}$ & $\mathrm{B}$ & $\mathrm{B}$ & $\mathrm{B}$ & $\mathrm{B}$ & $\mathrm{B}$ & $\mathrm{B}$ & $\mathrm{B}$ \\
\hline
\end{tabular}

Table 4. Fuzzy tuning rules for $k_{d j}^{\prime}[31]$

\begin{tabular}{|c|c|c|c|c|c|c|c|}
\hline$\Delta e_{j}$ & $\mathrm{NB}$ & $\mathrm{NM}$ & $\mathrm{NS}$ & $\mathrm{ZE}$ & $\mathrm{PS}$ & $\mathrm{PM}$ & $\mathrm{PB}$ \\
\hline $\mathrm{NB}$ & $\mathrm{B}$ & $\mathrm{B}$ & $\mathrm{B}$ & $\mathrm{B}$ & $\mathrm{B}$ & $\mathrm{B}$ & $\mathrm{B}$ \\
\hline $\mathrm{NM}$ & $\mathrm{M}$ & $\mathrm{M}$ & $\mathrm{B}$ & $\mathrm{B}$ & $\mathrm{B}$ & $\mathrm{M}$ & $\mathrm{M}$ \\
\hline $\mathrm{NS}$ & $\mathrm{S}$ & $\mathrm{M}$ & $\mathrm{M}$ & $\mathrm{B}$ & $\mathrm{M}$ & $\mathrm{M}$ & $\mathrm{S}$ \\
\hline $\mathrm{ZE}$ & $\mathrm{ZE}$ & $\mathrm{S}$ & $\mathrm{M}$ & $\mathrm{B}$ & $\mathrm{M}$ & $\mathrm{S}$ & $\mathrm{ZE}$ \\
\hline $\mathrm{PS}$ & $\mathrm{S}$ & $\mathrm{M}$ & $\mathrm{M}$ & $\mathrm{B}$ & $\mathrm{M}$ & $\mathrm{M}$ & $\mathrm{S}$ \\
\hline $\mathrm{PM}$ & $\mathrm{M}$ & $\mathrm{M}$ & $\mathrm{B}$ & $\mathrm{B}$ & $\mathrm{B}$ & $\mathrm{M}$ & $\mathrm{M}$ \\
\hline $\mathrm{PB}$ & $\mathrm{B}$ & $\mathrm{B}$ & $\mathrm{B}$ & $\mathrm{B}$ & $\mathrm{B}$ & $\mathrm{B}$ & $\mathrm{B}$ \\
\hline
\end{tabular}

The generated surfaces are shown in Fig.6, Fig.7 and Fig.8.

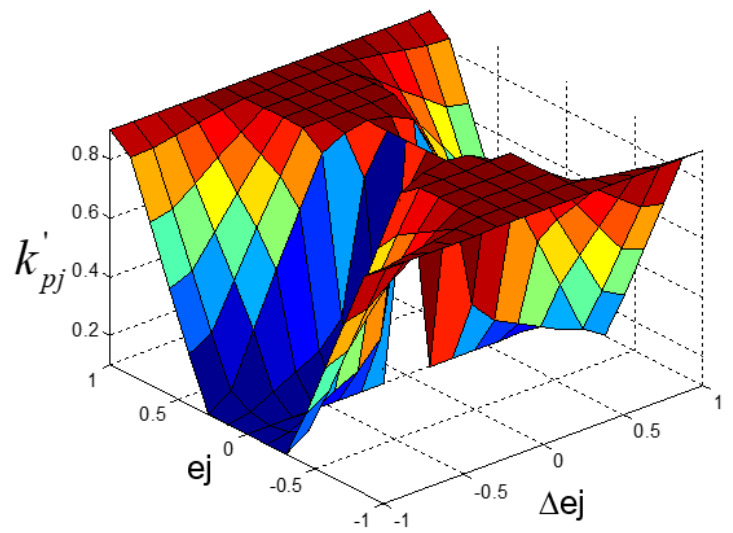

Figure 6. Surface of the gains $k_{p j}^{\prime}$ 


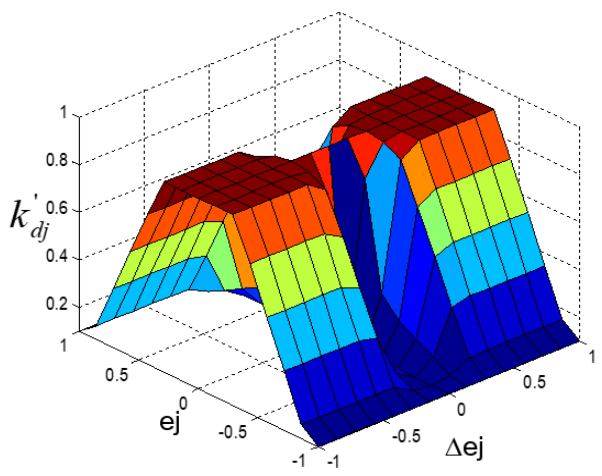

Figure 7. Surface of the gains $k_{d j}^{\prime}$

\section{SIMULATION RESULTS}

\subsection{Tracking control of square wave response}

The desired angles of the vertical and horizontal subsystem are chosen as square wave. The initial values of the $\psi$ and $\varphi$ angles are taken $(0,0)$ radians respectively. Fig.9 (a and b) illustrates the responses of the control system according to tracking a square trajectory for vertical, and horizontal angles

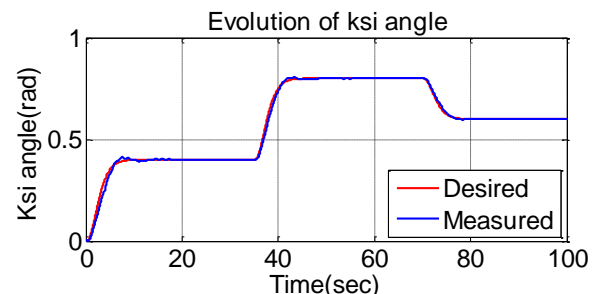

(a)

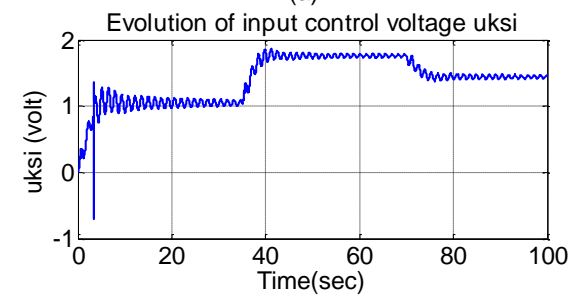

(c)

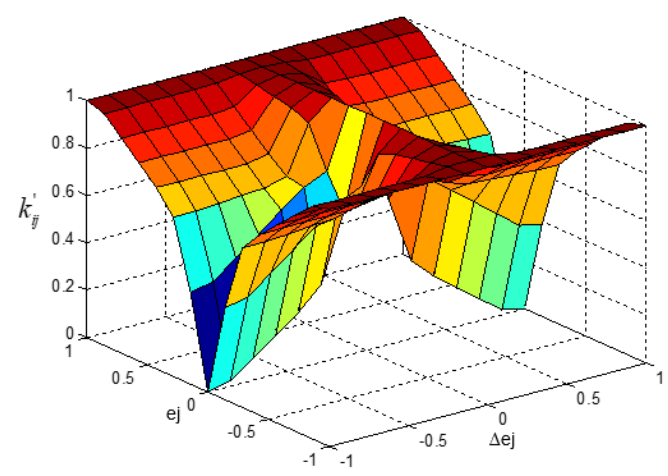

Figure 8. Surface of the gains $k_{i j}^{\prime}$

which show the ability of the proposed control system in the tracking problem.

In Fig.9 (c and d) we remark that the actual control input voltages for the two DC motors are confined in the permitted interval of $[-2.5,2.5]$ volts in fact the elimination of the chattering problem permits the smoothness of the control law. The adaptive gain parameters $\left(k_{p \psi}, k_{i \psi}, k_{d \psi}\right)$ and $\left(k_{p \varphi}, k_{i \varphi}, k_{d \varphi}\right)$ for the square response are show in Fig.10 (a, b and c) and Fig.11 ( $a, b$ and $c)$.

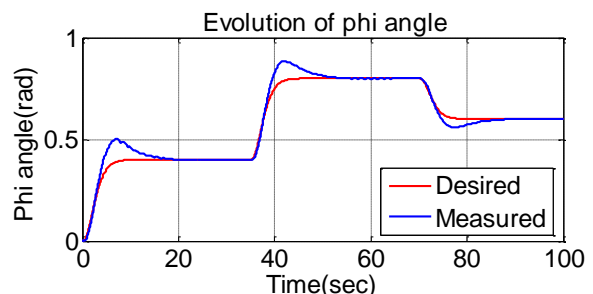

(b)

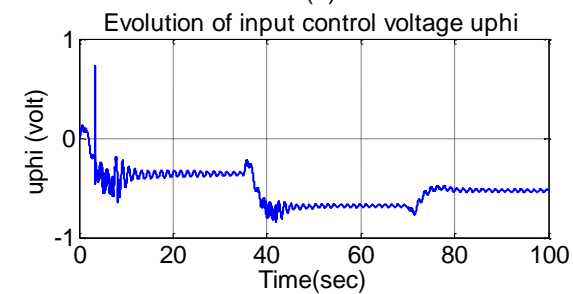

(d)

Figure 9. Simulation results of the square signal tracking
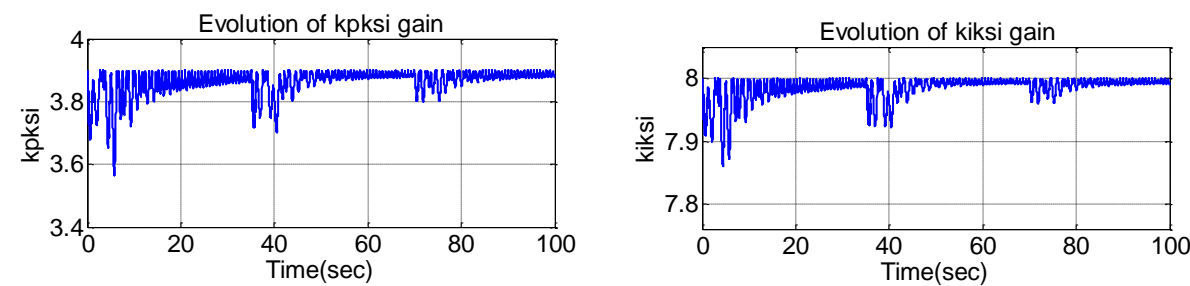

(a)

(b)

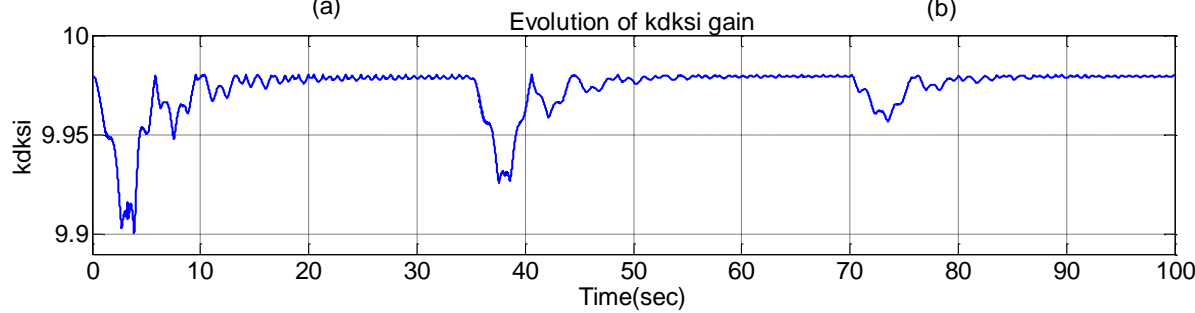

(c)

Figure 10. Gains $K_{p \psi}, K_{i \psi}$ and $K_{d \psi}$ of FGSPID control (square signal tracking) 


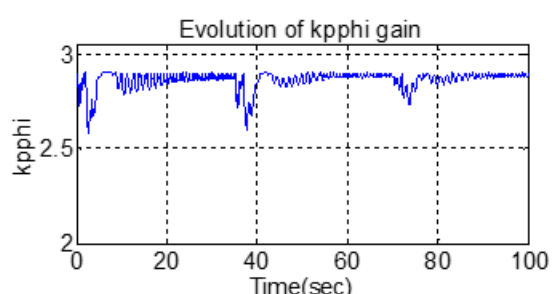

(a)

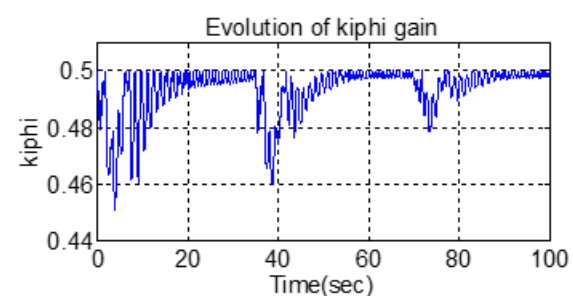

(b)

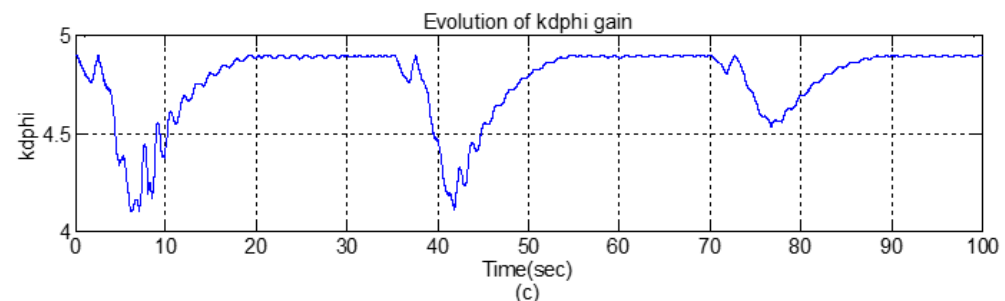

(c)

Figure 11. Gains $K_{p \varphi}, K_{i \varphi}$ and $K_{d \varphi}$ of FGSPID control (square signal tracking)

\subsection{Tracking control of high speed trajectory}

Fig.12 ( $\mathrm{a}$ and b) illustrates the responses of the control system according to high speed trajectory for $\psi$ and $\varphi$ angles which show the ability of the proposed control system in the tracking problem. The actual control input voltages for main and tail DC motors are confined in the permitted interval of [$2.5,2.5$ ] volts as shown in Fig.12 (c and d). The adaptive gain parameters $\left(k_{p \psi}, k_{i \psi}, k_{d \psi}\right)$ and $\left(k_{p \varphi}, k_{i \varphi}, k_{d \varphi}\right)$ for the high speed trajectory response are show in Fig.13 (a, b and c) and Fig.14 ( $a, b$ and $c)$.

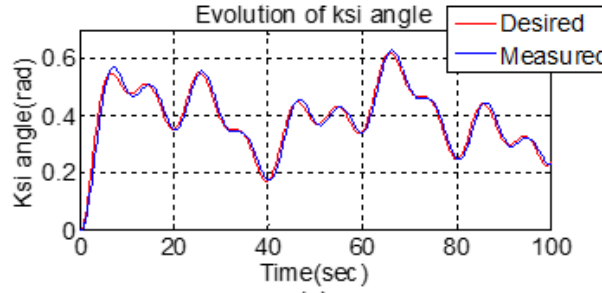

(a)

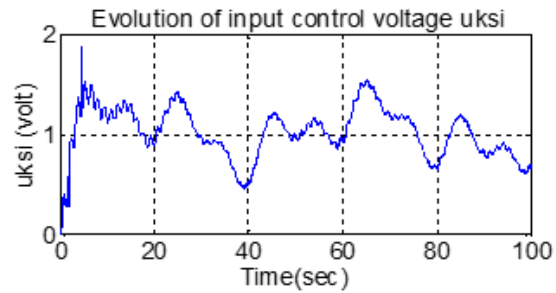

(c)

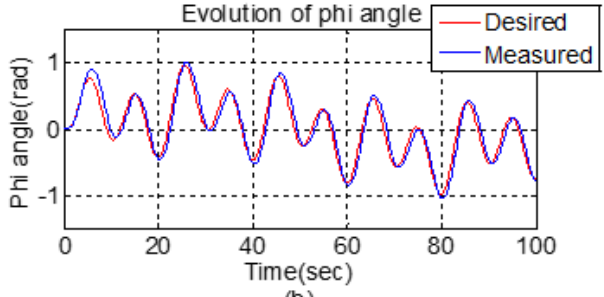

(b)

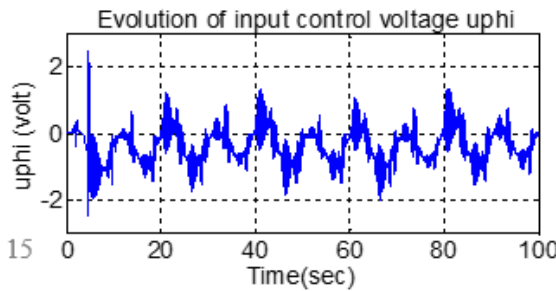

(d)

Figure 12. Simulation results of the high speed trajectory tracking
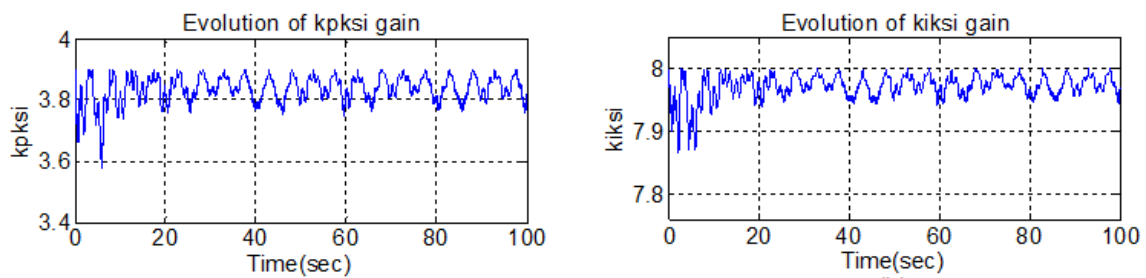

(b)

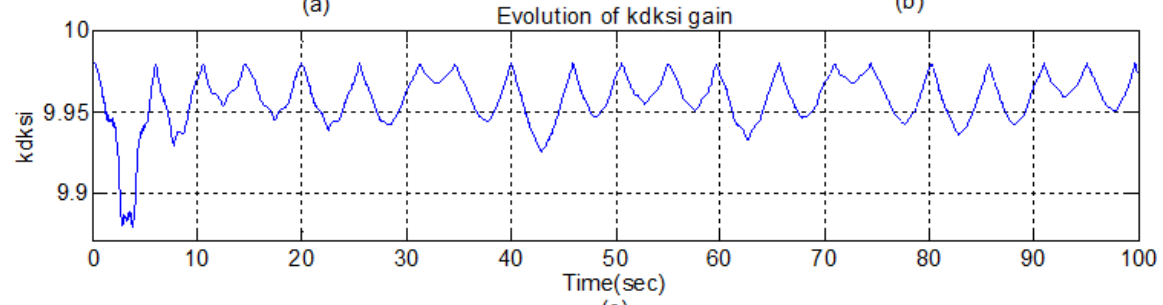

(c)

Figure 13. Gains $K_{p \psi}, K_{i \psi}$ and $K_{d \psi}$ of FGSPID control (high speed trajectory tracking) 


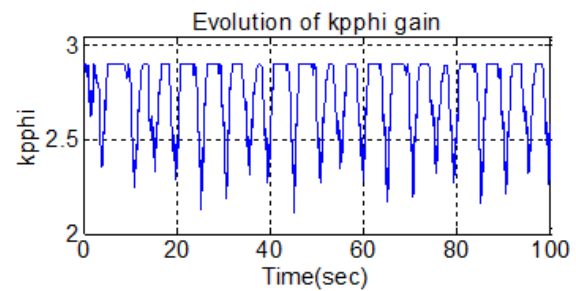

(a)

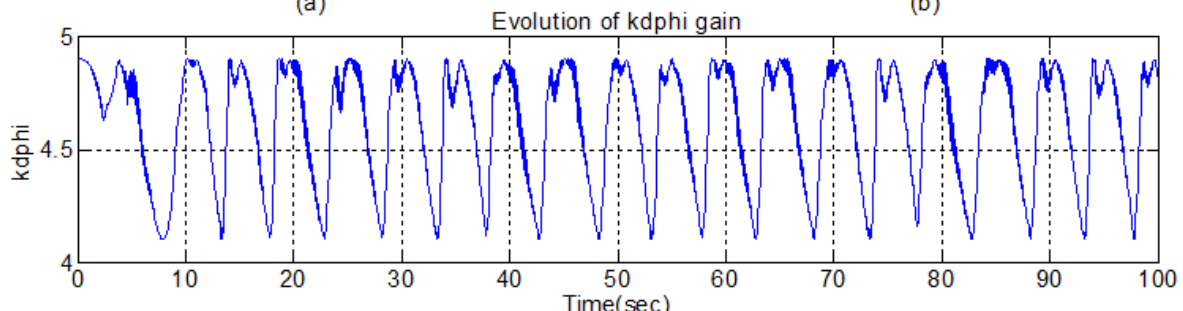

(c)

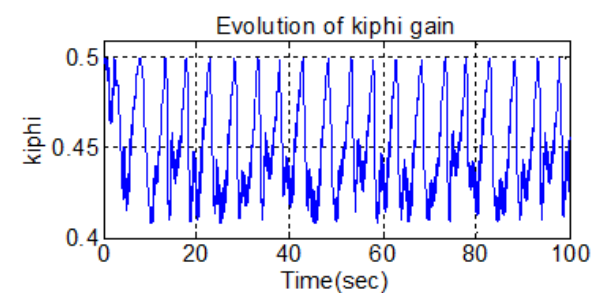

(b)

Figure 14. Gains $K_{p \varphi}, K_{i \varphi}$ and $K_{d \varphi}$ of FGSPID control (high speed trajectory tracking)

\section{EXPERIMENTAL RESULTS}

The complete set up of TRMS platform is shown in Fig.15. The system consists of four main elements [27].

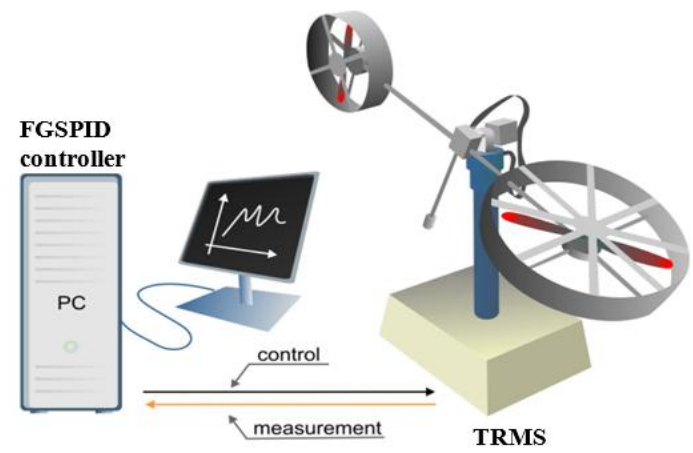

Figure 15. TRMS platform experiment [27]
- PC with a clocked control algorithm,

- $\quad \mathrm{A} / \mathrm{D}$ and $\mathrm{D} / \mathrm{A}$ converters - serving as an interface between the $\mathrm{PC}$ and external environment,

- The controlled process,

- sensors.

PCI $1711 \mathrm{Lab}$ is a universal Feedback unit having two blocks, Feedback encoder block and Feedback DAC block. For the TRMS two encoders are used thus the values of the $(\psi)$ and $(\varphi)$ are returned in Feedback encoder block. There are three parameters for this block: sample time, i.e. $0.001 \mathrm{sec}$, channel one and channel two offsets. Channel one refers to the first encoder output $(\psi)$ and channel two to the second encoder output $(\varphi)$. The digital input value given to PCI1711 is converted to analog output by Feedback DAC block. The proposed FGSPID controller is implemented in real-time using MATLAB real-time toolbox as shown in Fig.16. To show the performance of the proposed approach, experimental tests are given for trajectory tracking problems of the TRMS.

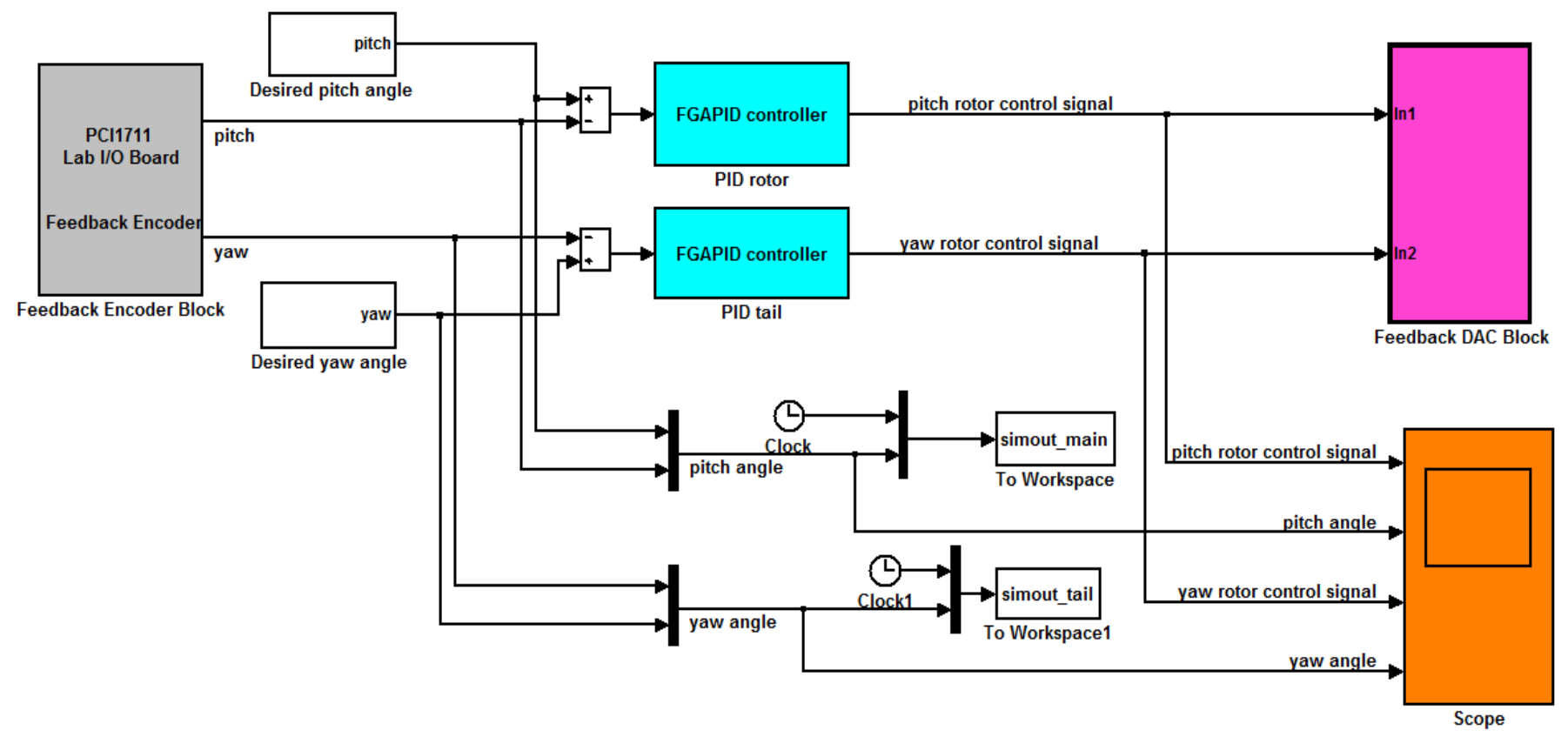

Figure 16. The proposed FGSPID controller implemented in real-time using MATLAB real-time toolbox 


\subsection{Tracking control experiment of square wave response}

Fig.17 ( $a$ and b) illustrates the responses of the control system according to square reference signals for pitch and yaw angles which show the ability of the proposed control system in the tracking problem. In addition, Fig.17 (c and d), indicate that the actual control voltage $u_{\psi}$ and $u_{\varphi}$ for main and tail DC

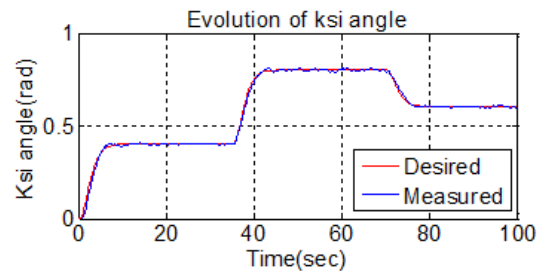

(a)

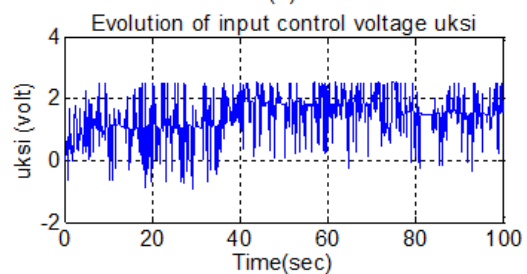

(c) motors are confined in the permitted interval of $[-2.5,2.5]$ volts and the chattering effect is eliminated. It is clear here that the peaking phenomena occurred in control signals is due to the discontinuous nature of the challenging square reference signals. The adaptive gain parameters $\left(k_{p \psi}, k_{i \psi}, k_{d \psi}\right)$ and $\left(k_{p \varphi}\right.$, $\left.k_{i \varphi}, k_{d \varphi}\right)$ for the square response experiment are show in Fig.18 (a, b and c) and Fig.19 (a, b and c).

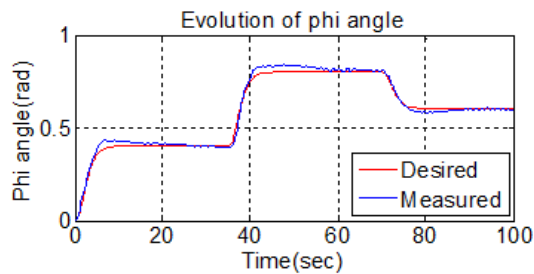

(b)

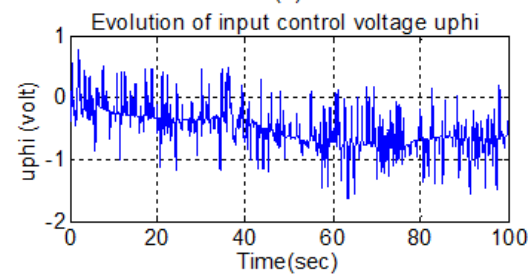

(d)

Figure 17. Experimental results of the square signal tracking

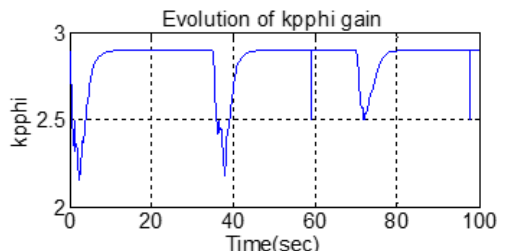

(a)

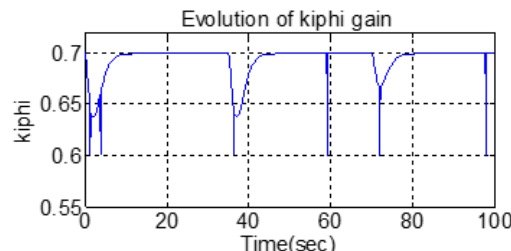

(b)

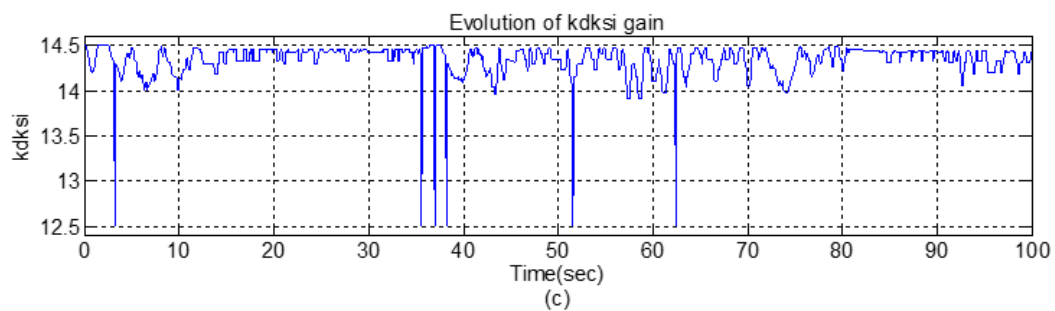

Figure 18. Gains $K_{p \psi}, K_{i \psi}$ and $K_{d \psi}$ of FGSPID control (square signal tracking)

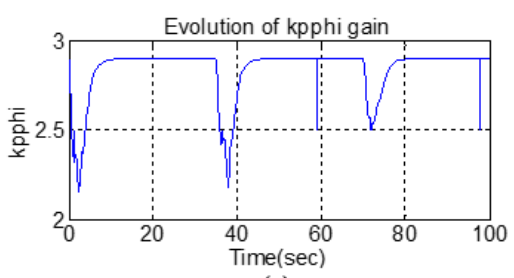

(a)

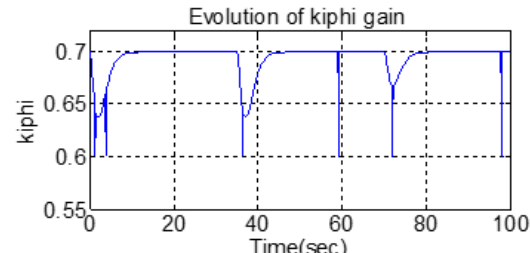

(b)

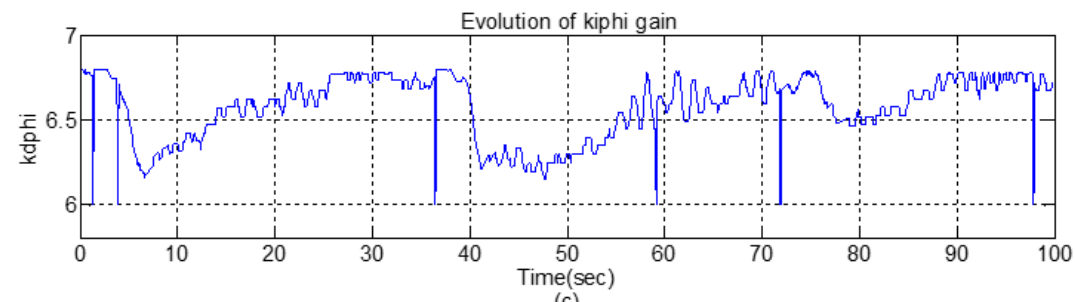

(c)

Figure 19. Gains $K_{p \varphi}, K_{i \varphi}$ and $K_{d \varphi}$ of FGSPID control (square signal tracking) 


\subsection{Tracking control experiment of high speed trajectory}

The tracking responses experiment are shown in Fig.20 (a and $b$ ). From the results, it is noted that the proposed controller can result in great tracking responses. On the other hand, from Figs.20 (c and d), it can be seen that the control signals are quite smooth and the actual control input voltages for main and tail DC motors are confined in the permitted interval of [-2.5, $2.5]$ volts. The adaptive gain parameters $\left(k_{p \psi}, k_{i \psi}, k_{d \psi}\right)$ and $\left(k_{p \varphi}\right.$, $\left.k_{i \varphi}, k_{d \varphi}\right)$ for the high speed trajectory response experiment are show in Fig.21 ( $\mathrm{a}, \mathrm{b}$ and $\mathrm{c}$ ) and Fig.22 ( $\mathrm{a}, \mathrm{b}$ and $\mathrm{c}$ ). In all test cases, the controller is efficient to maintain the angles close to their desired values after transient deviations.

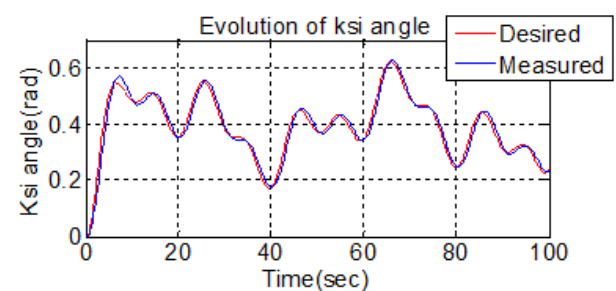

(a)

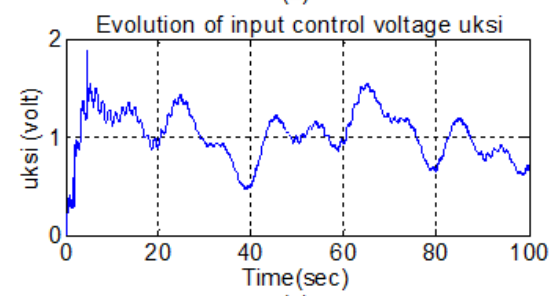

(c)

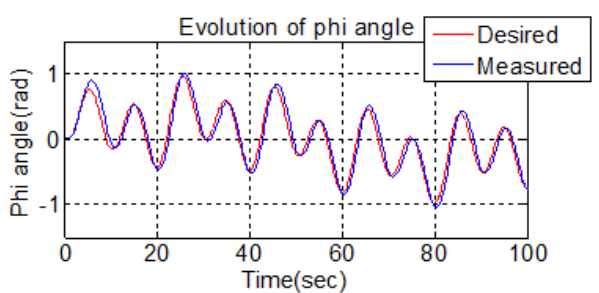

(b)

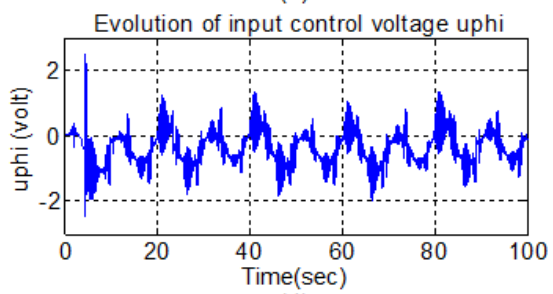

(d)

Figure 20. Experimental results of the high speed trajectory tracking

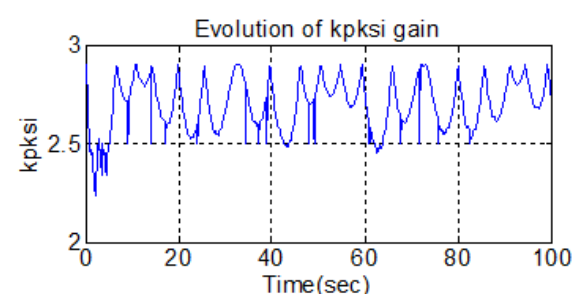

(a)

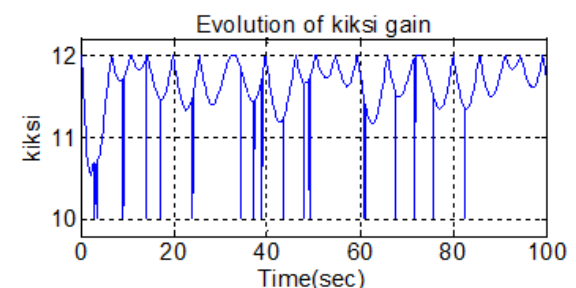

(b)

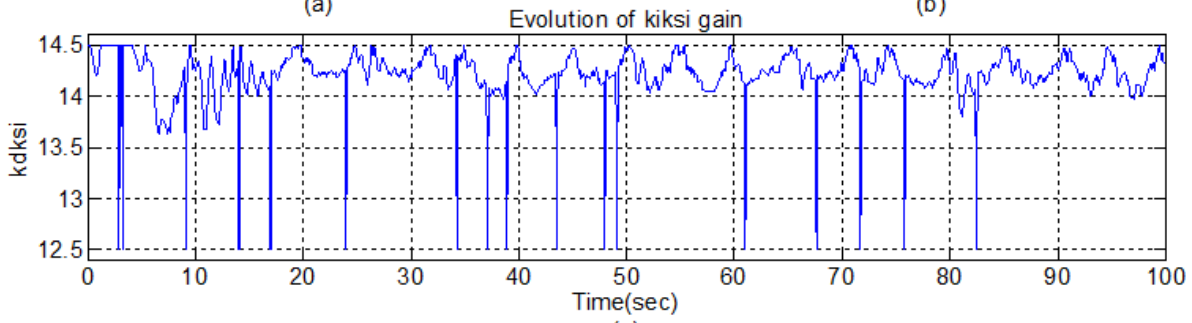

(c)

Figure 21. Gains $K_{p \psi}, K_{i \psi}$ and $K_{d \psi}$ of FGSPID control (high speed trajectory tracking)


Figure 22. Gains $K_{p \varphi}, K_{i \varphi}$ and $K_{d \varphi}$ of FGSPID control (high speed trajectory tracking) 


\subsection{Robustness to the external disturbances}

To evaluate the robustness of the proposed FGSPID controller, an external disturbance were introduced to the system at $\mathrm{t}=32 \mathrm{~s}$ and $\mathrm{t}=62 \mathrm{~s}$. The experiment results are depicted in Fig.23 ( $a$ and $b$ ) which shows that the controller is immune recovers adequately for the external perturbation. The peaking phenomenon appears in the input voltages $u_{v}$ and $u_{h}$, as shown in Fig.23 (c and d), represents the transient of the adaptation to compensate the sudden change of TRMS angles caused by perturbation. The adaptive gain parameters $\left(k_{p \psi}, k_{i \psi}, k_{d \psi}\right)$ and $\left(k_{p \varphi}, k_{i \varphi}, k_{d \varphi}\right)$ for the Robustness test experiment are show in Fig.24 (a, b and c) and Fig.25 (a, b and c).

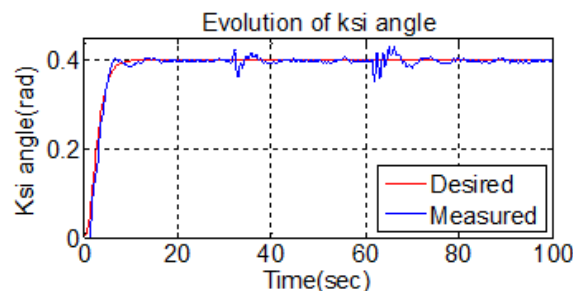

(a)

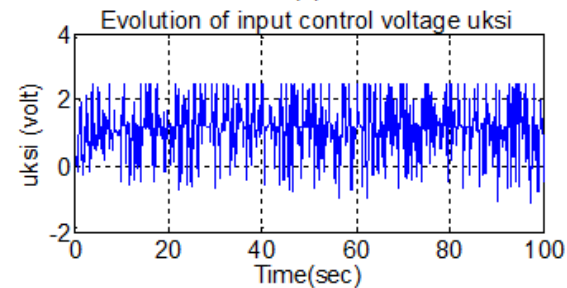

(c)

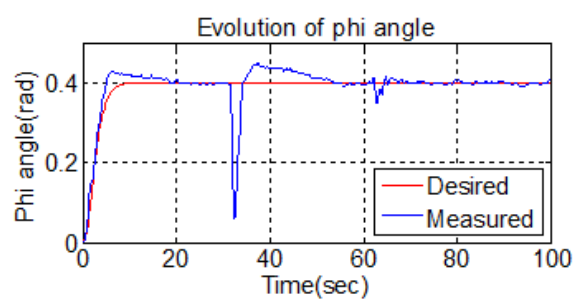

(b)

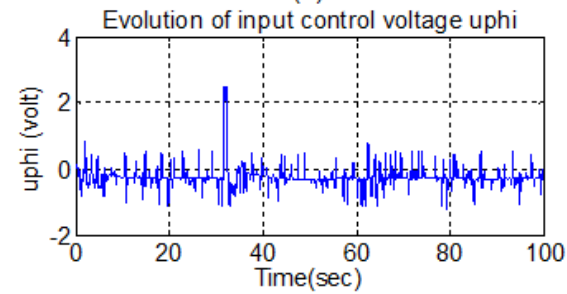

(d)

Figure 23. Step responses of the TRMS with the proposed FGSPID controller subject to the external disturbance

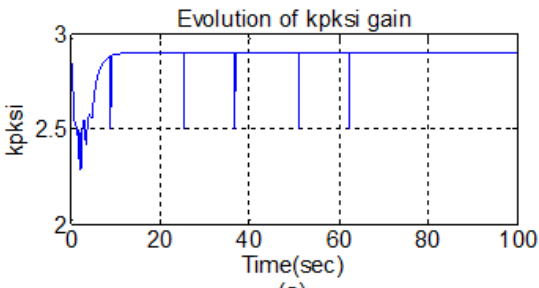

(a)

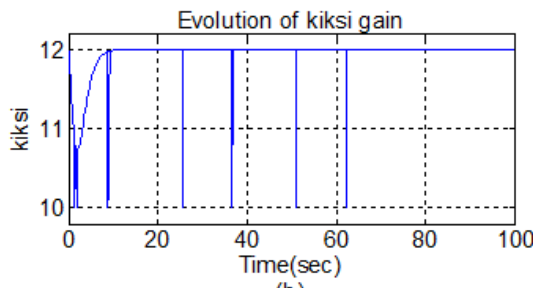

(b)

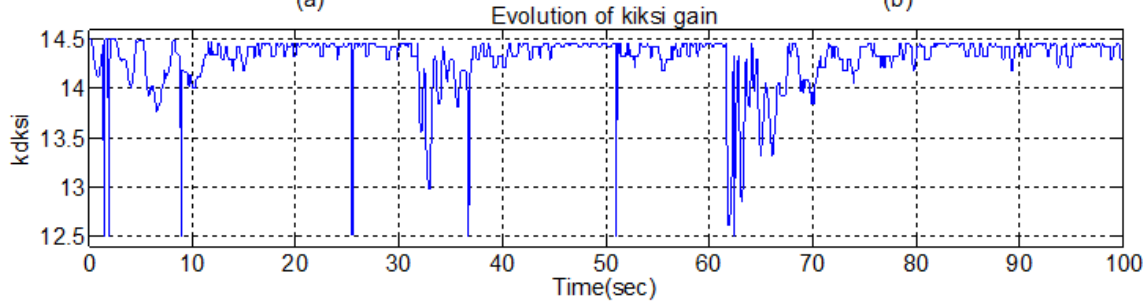

(c)

Figure 24. Gains $K_{p \psi}, K_{i \psi}$ and $K_{d \psi}$ of FGSPID control (external disturbance rejection)
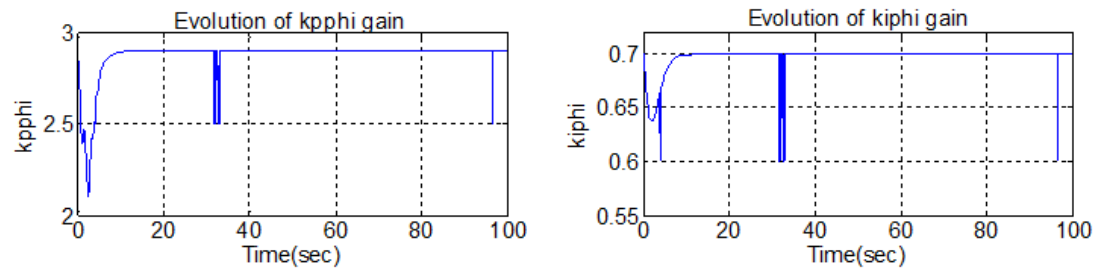

(b)

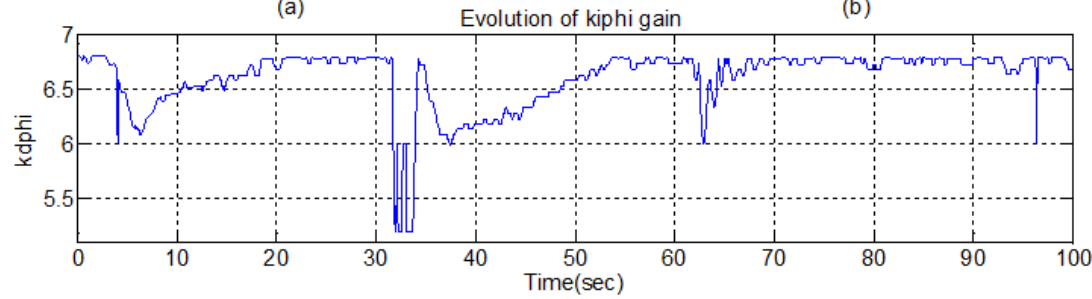

(c)

Figure 25. Gains $K_{p \varphi}, K_{i \varphi}$ and $K_{d \varphi}$ of FGSPID control (external disturbance rejection) 
In the present study, an integral of the absolute value of the error (IAE), Integral of square error (ISE), and integral of the time multiplied by the absolute value of the error (ITAE), are utilized to judge the performance of the controller. IAE, ISE and ITAE criteria are widely adopted to evaluate the dynamic performance of the control system [32]. The indexes IAE, ISE and ITAE are expressed as follows

$$
I A E=\int_{0}^{T}|e(t)| d t, \quad I S E=\int_{0}^{T} e^{2}(t) d t, \quad I T A E=\int_{0}^{T} t|e(t)| d t
$$

To compare the performances of the proposed FGSPID controller between the adaptive second-order sliding mode controller (ASOSMC) proposed in [10], the ProportionalIntegral- Differential (PID) control with optimised parameters using genetic algorithm (GA) presented in [13] and the
Proportional-Integral-Differential (PID) control with optimised parameters using particle swarm optimization (PSO) presented in [33], IAE, ISE and ITAE are used as the comparison criteria. Table. 5 shows the IAE, ISE and ITAE values of the experiment results using ASOSMC, PID control optimized by (GA), PID control optimized by (PSO) and FGSPID controller. For the previous testes it is noted that the proposed FGSPID offers the smallest values control of IAE, ISE and ITAE, whereas the PID control optimized by (GA) present the largest values of IAE, ISE and ITAE for both vertical and horizontal subsystems. It can be seen that the system performances are better, during square signal tracking and high speed trajectory tracking, when using the proposed FGSPID controller as compared to the ASOSMC, PID control optimized by (GA) and PID control optimized by (PSO) controllers.

Table 5. Quantitative comparison between the proposed controller, ASOSMC Controller, PID controller optimized by (GA) and PID controller optimized by (PSO)

\begin{tabular}{|c|c|c|c|c|c|c|c|}
\hline \multirow[b]{2}{*}{ Test } & \multirow{2}{*}{$\begin{array}{l}\text { Control } \\
\text { scheme }\end{array}$} & \multicolumn{2}{|c|}{ IAE } & \multicolumn{2}{|c|}{ ISE } & \multicolumn{2}{|c|}{ ITAE } \\
\hline & & $\begin{array}{c}(\psi \\
\text { ngle })\end{array}$ & $\begin{array}{c}(\varphi \\
\text { angle })\end{array}$ & $\begin{array}{c}(\psi \\
\text { ngle })\end{array}$ & $\begin{array}{c}(\varphi \\
\text { angle })\end{array}$ & $\begin{array}{c}(\psi \\
\text { ngle })\end{array}$ & $\begin{array}{c}(\varphi \\
\text { angle })\end{array}$ \\
\hline \multirow{4}{*}{$\begin{array}{l}\text { Square signal } \\
\text { tracking }\end{array}$} & ASOSMC proposed in [10] & 0.66 & 1.705 & 0.0087 & 0.0453 & 0.968 & 2.424 \\
\hline & PID control optimized by (GA) proposed in [13] & 0.752 & 1.989 & 0.0102 & 0.0529 & 1.468 & 2.828 \\
\hline & PID control optimized by (PSO) proposed in [33] & 0.715 & 1.847 & 0.0094 & 0.0491 & 1.049 & 2.626 \\
\hline & The proposed FGSPID & 0.550 & 1.421 & 0.0073 & 0.0378 & 0.807 & 2.02 \\
\hline \multirow{4}{*}{$\begin{array}{l}\text { High speed } \\
\text { trajectory tracking }\end{array}$} & $\begin{array}{l}\text { ASOSMC } \\
\text { proposed in [10] }\end{array}$ & 1.376 & 2.467 & 0.0250 & 0.148 & 1.506 & 3.692 \\
\hline & PID control optimized by (GA) proposed in [13] & 1.605 & 2.878 & 0.0363 & 0.175 & 2.284 & 4.272 \\
\hline & PID control optimized by (PSO) proposed in [33] & 1.491 & 2.672 & 0.0271 & 0.1647 & 1.632 & 3.968 \\
\hline & The proposed FGSPID & 1.147 & 2.056 & 0.0209 & 0.125 & 1.256 & 3.05 \\
\hline
\end{tabular}

\section{CONCLUSION}

This paper addressed the design of fuzzy gain-scheduled PID controller for a TRMS system in the presence of the yaw and pitch external disturbances. Firstly, we start by the development of the dynamic model of the TRMS taking into account the different physics phenomena. A highly coupled nonlinear TRMS is decomposed into a set of main and tail subsystems with the coupling effect considered as the uncertainties. Simulation and experimental results are presented to show the effectiveness of the proposed method. In addition the comparative study performed with other works developed in the literature, has shown the effectiveness of the proposed control approach in the tracking performances of the angles.

\section{REFERENCES}

[1] Bouguerra A, Saigaa D, Kara K, Zeghlache S. (2015). Fault-tolerant Lyapunov-gain-scheduled PID control of a quadrotor UAV. International Journal of Intelligent Engineering and Systems 8(2): 1-6

[2] Zeghlache S, Amardjia (2018). Real time implementation of non linear observer-based fuzzy sliding mode controller for a twin rotor multi-input multioutput system (TRMS). Optik - International Journal for Light and Electron Optics 156: 391-407.
[3] Tee KP, Ge SS, Tay FEH. (2008). Adaptive neural network control for helicopters in vertical flight. IEEE Transaction on Control Systems Technology 16: 753-762. https://doi.org/10.1109/TCST.2007.912242

[4] Wen P, Lu TW. (2008). Decoupling control of a twin rotor MIMO system using robust deadbeat control technique. IET Control Theory and Applications 11: 9991007. https://doi.org/10.1049/iet-cta:20070335

[5] Chelhi A, Chemachema M. (2014). Model reference adaptive control for twin rotor multiple-input and multiple-output system via minimal controller synthesis. Proceedings of the Institution of Mechanical Engineers, Part I: Journal of Systems and Control Engineering 228: 406-418.

[6] Tao C, Taurb J, Chen Y. (2010). Design of a parallel distributed fuzzy LQR controller for the twin rotor multiinput multi-output system. Fuzzy Sets and Systems 161: 2081-2103. https://doi.org/10.1016/j.fss.2009.12.007

[7] Edwards C, Spurgeon K. (1998). Sliding mode control: theory and applications. Taylor and Fransic, London. ISBN 0-7484-0601-8.

[8] Ramy R, Ayman E, Ahmed A. (2017). Sliding mode disturbance observer-based of a twin rotor MIMO system. ISA transactions 69: 166-174. https://doi.org/10.1016/j.isatra.2017.04.013

[9] Anup K, Srinivasan N, Mahindrakar A. (2011). Terminal sliding mode control of a twin rotor multiple-input multiple-output system. IFAC World Congress, 
IFAC'2011, Milano, Italy, September 2011, Proc. 10952-10957.

[10] Mondal S, Mahanta C. (2012). Adaptive second-order sliding mode controller for a twin rotor multi-inputmulti-output system. IET on Control Theory \& Applications 14: 2157-2167. https://doi.org/10.1049/ietcta. 2011.0478

[11] Faris F, Moussaoui A, Boukhetala D, Tadjine M. (2017). Design and real-time implementation of a decentralized sliding mode controller for twin rotor multi-input multioutput system. Journal of Systems and Control Engineering 231: 3-13.

[12] Ziegler JG, Nichols NB. (1942). Optimum settings for automatic controllers. ASME Trans 64: 759-768.

[13] Jih-Gau J, Ming-Te H, Wen-Kai L. (2016). PID control using presearched genetic algorithms for a MIMO system. IEEE Systems, Man, and Cybernetics Society 38: 716-727. https://doi.org/10.1109/TSMCC.2008.923890

[14] Ayan S, Sarbani C. (2016). Genetic algorithm based IPD controller design for Twin Rotor MIMO system. IEEE International Conference on Control, Instrumentation, Energy \& Communication, Kolkata, India, January 2016, Proc. 15-19. https://doi.org/10.1109/CIEC.2016.7513826

[15] Yu K, Hsu J. (2008). Fuzzy gain scheduling PID control design based on particle swarm optimization method. IEEE International Conference on Innovative Computing, Information and Control, Kumamoto, Japan, September 2007 , Proc.

$1-6$. https://doi.org/10.1109/ICICIC.2007.323

[16] Zulfatman, Rahmat MF. (2009). Application of selftuning fuzzy PID controller on industrial hydraulic actuator using system identification approach. Int. J. on Smart Sensing and Intelligent Systems 2: 246-261.

[17] Guo Y, Yang T. (2010). A new type of computational verb gain-scheduling PID controller. IEEE International Conference on Counterfeiting Security and Identification in Communication, Chengdu, China, July 2010, Proc. 16. https://doi.org/10.1109/ICASID.2010.5551490

[18] Yao L, Lin C. (2005). Design of gain scheduled fuzzy PID controller. World Academy of Science, Engineering and Technology 1: 152-156.

[19] El Emary IMM, Emar W, Aqel MJ. (2009). The adaptive fuzzy designed PID controller using wavelet network. Journal of Computer Science and Information System 1: 6141-6163.

[20] Juang JG, Lin RW, Liu WK. (2008). Comparison of classical control and intelligent control for MIMO system. Applied Mathematics and Computation 205: 778-791. https://doi.org/10.1016/j.amc.2008.05.061

[21] Jih-Gau J, Kai-Ti T. (2013). Design and realization of a hybrid intelligent controller for a twin rotor MIMO system. Journal of Marine Science and Technology 21: $333-341$
[22] Karray F, Gueaieb W, Al-Sharhan S. (2002). The hierarchical expert tuning of PID controllers using tools of soft computing. IEEE Trans. Systems. Man, and

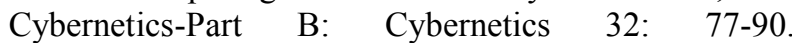
https://doi.org/10.1109/3477.979962

[23] Zhao Z, Tomizuka M, Isaka S. (1993). Fuzzy gain scheduling of PID controllers. IEEE Trans. Systems. Man, and Cybernetics 23: 1392-1398. https://doi.org/1 $0.1109 / 21.260670$

[24] Hu B, Mann GKI, Gosine RG. (2001). A systematic study of fuzzy PID controllers-function-based evaluation approach. IEEE Trans. Fuzzy Systems 9: 699-712. https://doi.org/10.1109/91.963756

[25] Ramalakshmi APS, Manoharan PS. (2012). Non-linear modeling and PID control of twin rotor MIMO system. IEEE International Conference on Advanced Communication Control and Computing Technologies, Ramanathapuram, India, August 2012, Proc. 1-6. https://doi.org/10.1109/ICACCCT.2012.6320804

[26] Sumit KP, Vijaya L. (2014). Control of twin rotor MIMO system using PID controller with derivative filter coefficient. IEEE International Conference on Electrical, Electronics and Computer Science, Bhopal, India, March 2014, Proc. 1-6. https://doi.org/10.1109/SCEECS.2014.6804451

[27] Ltd FI. (2006). Twin Rotor MIMO System Manual, Feedback Instruments Ltd., UK, 2006.

[28] Meliani B, Meroufel A, Khouidmi H. (2012). Fuzzy gain scheduling of PI controller for dual star induction machine fed by a matrix converter. Carpathian Journal of Electronic and Computer Engineering 6: 77-82.

[29] Hazzab A, Bousserhane I.K, Zerbo M, Sicard P. (2006). Real time implementation of fuzzy gain scheduling of PI controller for induction motor machine control. Neural Processing Letters 24: 203-215. https://doi.org/10.1007/s11063-006-9018-5

[30] Jeyalakshmi V, Murugan S. (2010). On line tuning of intelligent controller for induction drive system. International Journal of Engineering Science and Technology 10: 5350-5356

[31] Mohammad HA, Abbas C, Youmin Z. (2012). Faulttolerant fuzzy gain-scheduled PID for a quadrotor helicopter testbed in the presence of actuator faults. IFAC Conference on Advances in PID Control, Brescia, Italy, March 2012, Proc. 1-6. https://doi.org/10.3182/20120328-3-IT-3014.00048

[32] Castillo O, Melin P. (2008). Type-2 fuzzy logic. Theory and Applications. Berlin, Germany: Springer-Verlag.

[33] Pramit B, Roshni M, Anirban K, Kaushik D, Gautam S. (2014). PSO based PID controller design for twin rotor MIMO system. IEEE International Conference on Control, Instrumentation, Energy \& Communication, Calcutta, India, November 2014, Proc 1-6. https://doi.org/10.1109/CIEC.2014.6959049 